\title{
A Backscattering and Propagation Model for Radar Sounding of Ice Sheets
}

\author{
Dall, Jørgen
}

Published in:

Proceedings of the 2016 IEEE International Geoscience and Remote Sensing Symposium (IGARSS 2016)

Link to article, DOI:

10.1109/IGARSS.2016.7730849

Publication date:

2016

Document Version

Peer reviewed version

Link back to DTU Orbit

Citation (APA):

Dall, J. (2016). A Backscattering and Propagation Model for Radar Sounding of Ice Sheets. In Proceedings of the 2016 IEEE International Geoscience and Remote Sensing Symposium (IGARSS 2016) (pp. 7088-7091). IEEE. https://doi.org/10.1109/IGARSS.2016.7730849

\section{General rights}

Copyright and moral rights for the publications made accessible in the public portal are retained by the authors and/or other copyright owners and it is a condition of accessing publications that users recognise and abide by the legal requirements associated with these rights.

- Users may download and print one copy of any publication from the public portal for the purpose of private study or research.

- You may not further distribute the material or use it for any profit-making activity or commercial gain

- You may freely distribute the URL identifying the publication in the public portal

If you believe that this document breaches copyright please contact us providing details, and we will remove access to the work immediately and investigate your claim. 


\title{
A BACKSCATTERING AND PROPAGATION MODEL FOR RADAR SOUNDING OF ICE SHEETS
}

\author{
Jørgen Dall \\ Technical University of Denmark, Kongens Lyngby, Denmark; email: jd@ space.dtu.dk
}

\begin{abstract}
In this paper the electromagnetic properties of the continental ice sheets are modeled with the aim of assessing the feasibility of space-based radar ice sounding at P-band. The paper focuses on the model itself, as distinct from the estimation of model parameters and the exploitation of the model. The scattering and propagation properties of the ice sheets are characterized using an empirical approach. The model comprises surface scattering from the air/ice interface and the ice/bed interface as well as volume scattering from the firn and the ice. Also specular reflection from the internal layers is modeled. In combination with simple models of the ice sounding radar and the geometry, the electromagnetic model estimates the return waveform and its constituents, such that sensitivity and clutter masking issues can be assessed.
\end{abstract}

Index Terms - Radar, sounding, electromagnetic model, P-band, ice sheets, Antarctica

\section{INTRODUCTION}

Space-based radar sounding of the continental ice sheets can potentially offer full coverage, uniform data quality and sampling. Ice sounding radars must operate at low frequencies in order to ensure low attenuation of the signal as it propagates down through the ice and back from the base of the ice sheet. Typical frequencies of airborne radar ice sounders are $60 \mathrm{MHz}$ and $150 \mathrm{MHz}$. However, the lowest possible frequency for space-based radar ice sounders is $435 \mathrm{MHz}$. In 2004 the radio regulations of the International Telecommunication Union (ITU) allocated a $6 \mathrm{MHz}$ band at $435 \mathrm{MHz}$ (P-band) enabling space-based Earth observation radar missions at a frequency that might be applicable for ice sounding.

This paper describes a backscattering and propagation model for radar sounding of ice sheets. The model was originally developed in parallel with the design of the Polarimetric Airborne Radar Ice Sounder (POLARIS) [1], but subsequently the model has been upgraded in order to assess the feasibility of space-based radar ice sounding. For that a two-step approach is applied:
(1) Key ice sheet model parameters are estimated from airborne POLARIS data acquired in Antarctica.

(2) The performance of a potential space-based ice sounding radar is estimated based on the ice sheet model, the parameters of the space-based and the data acquisition geometry.

At P-band the attenuation and scattering properties of the ice sheets are not as well known as they are at the lower frequencies commonly used from aircraft, but in 2005 the Technical University of Denmark was commissioned by ESA to development the POLARIS system [1], and encouraging results were obtained with data acquired in Greenland. In February 2011 POLARIS data were acquired in Antarctica as part of the IceGrav campaign [3], the primary objective of which was to measure gravity in Queen Maud Land, but a secondary objective was to acquire Pband sounder data, benefitting from the large coverage offered by the Basler DC3 aircraft used.

\section{METHODOLOGY}

The backscattering and propagation properties of the ice sheets can either be characterized empirically, or with analytical models like the Kirchhoff Model [4], the Small Perturbation Model [4], and the Picardi model [5]. The analytical approach is preferable if physical parameters like surface roughness and correlation length are of interest, but the analytical approach may be too simplistic for low frequency mapping of complex media like ice sheets. For the purpose in question the empirical approach suffices, i.e. the model parameters are surface and volume backscatter coefficients (including their angular dependency), reflection coefficients (for specular interfaces), and attenuation coefficients (accounting for both absorption and scattering).

The model parameters are estimated by tuning the parameters such that the modeled radar return waveform matches the measured POLARIS waveform. This procedure requires as input (1) the POLARIS system parameters and the data acquisition geometry, (2) scattering patterns estimated directly from the Doppler spectra of the POLARIS data (cf. Figure 1), and (3) ancillary data, i.e. ice sheet parameters from various observational studies. The parameter estimation methodology is presented in [2]. 


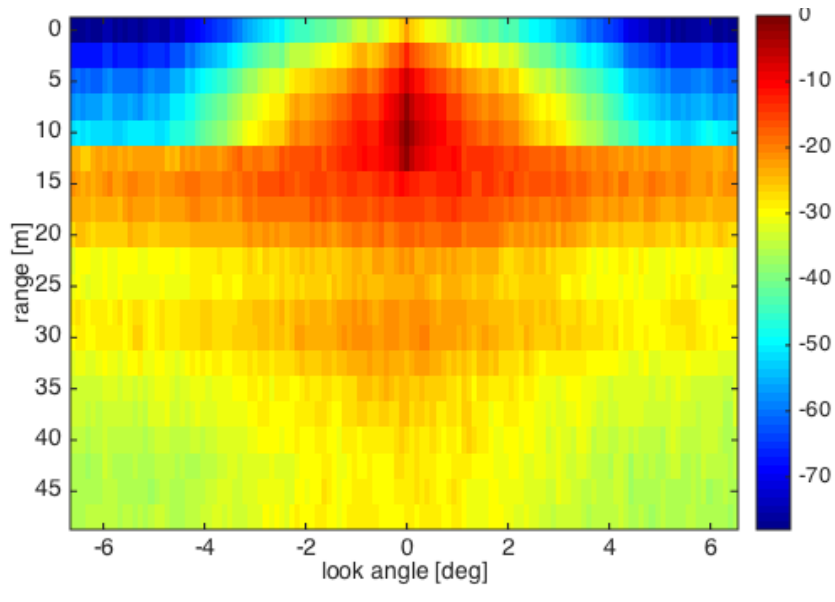

Figure 1 Scattering pattern of an ice shelf surface and the underlying firn layer (color scale in $\mathrm{dB}$ ). The surface is at a range of $10 \mathrm{~m}$.

\section{RETURN WAVEFORM CONTRIBUTIONS}

The ice sheet model can be combined with a radar system model in order to generate waveforms representing data that are either unfocused or focused and migration corrected in the along track direction. It is easy to compensate for the along track antenna pattern during focusing, but the resulting waveforms are still impacted by the variation of the scattering pattern within an angular interval defined by the synthetic aperture.

The contributors to the return waveform are the ice surface, the ice bed, internal layers (isochrones) and diffuse scatterers in the firn and in the ice. Figure 2 shows the geometry in the cross track plane. The pulse-limited footprint on the ice surface is an annular ring in the unfocused case and two small rectangles (to the right and to the left of the nadir point) in the focused case.

Internal layers contribute a signal with a very narrow scattering pattern (reflection only in the direction perpendicular to the surface), whereas diffuse scatterers result in a volume contribution with a wider scattering pattern (volume clutter). When using airborne data to assess the feasibility of space-based ice sounding it is important to discriminate between a near-nadir contribution and a surface (or near-surface) contribution with the same equivalent depth, i.e. the same two-way time delay. Surface clutter (or near-surface volume clutter) at a given incidence angle coincide with a much deeper nadir signal in the satellite case than in the aircraft case, and since the depth signal of interest is much more attenuated, it is likely to be masked by the clutter.

A narrow scattering pattern in combination with a small attenuation coefficient implies that most of the volume clutter is coming from near nadir, and it could actually be modelled like the contribution from the internal layers

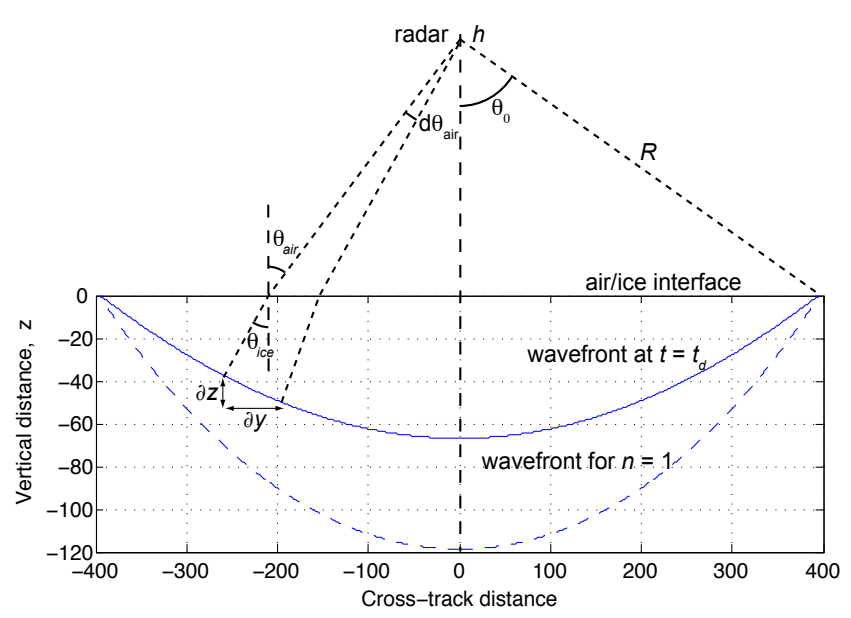

Figure 2 Ice sounding geometry. The dashed line illustrates the circular wavefront that would result if the ice had a refractive index of $n=1$.

(except for the different geometric spread). On the other hand, a wide scattering pattern implies significant volume clutter from the off-nadir, near-surface part of the slant range cell illustrated with the solid blue line in Figure 2.

\subsection{Surface contribution}

The surface clutter contribution is computed from the radar equation and the radar cross section, which in turn is the product of the surface backscattering coefficient $\sigma_{\text {surf }}^{0}$ and the area of the resolution cell $A_{\text {surf }}$ (annular ring or two rectangles for unfocused an focused data, respectively)

$$
\sigma=\sigma_{\text {surf }}^{0}(\theta) A_{\text {surf }}(\theta)
$$

Once $\sigma_{\text {surf }}^{0}(\theta)$ is estimated from the airborne ice sounder data, $\sigma$ can be computed for the satellite case using the system parameters of the space-based radar.

\subsection{Bed contribution}

Likewise, the bed signal is computed from the radar equation and the effective radar cross-section, which in turn depends on the two-way transmission coefficient at the air/ice interface and the attenuation that results from the two-way propagation through the ice. The model supports a depth-dependent attenuation. The refraction at the air/ice interface has a focusing effect, which is taken into account by including a refraction gain [6].

\subsection{Volume clutter contribution}

The volume clutter of a resolution cell in focused data is computed by integrating the power along the solid blue line in Figure 2. 


$$
P_{V} \approx \frac{\lambda^{2} G_{g} P_{t}}{(4 \pi)^{3} R^{4} L_{t x}} \int_{\theta_{a i r}=-\theta_{0}}^{\theta_{0}} G\left(\theta_{\text {air }}\right)^{2} \sigma_{e f f}^{0}\left(z, \theta_{i c e}\right) d V
$$

The parameters are:

$$
\begin{array}{ll}
\lambda & \text { wavelength } \\
G_{g} & \text { refractive gain } \\
P_{t} & \text { transmit power } \\
R & \text { range (electrical distance) } \\
L_{t x} & \text { system loss } \\
G & \text { antenna gain } \\
\theta_{\text {air }} & \text { cross track angle in air } \\
\theta_{i c e} & \text { cross track angle in ice } \\
\theta_{0} & \text { clutter angle = incidence angle at surface } \\
z & \text { equivalent depth (nadir depth corresponding to a } \\
& \text { given time delay) }
\end{array}
$$

The effective backscatter coefficient is:

$$
\sigma_{e f f}^{0}(z, \theta)=G_{g}(\theta)\left(1-R_{01}^{2}\left(\theta_{0}\right)\right)^{2} E(z, \theta) \sigma_{v o l}^{0}(z, \theta)
$$

It incorporates:

- the refraction gain $G_{g}$

- the two-way transmission coefficient of the air-ice interface $\left(1-R_{01}^{2}\left(\theta_{0}\right)\right)^{2}$

- the attenuation (or extinction) caused by two-way propagation through the ice $E(z, \theta)$

- the backscattering coefficient (radar cross section per unit volume) $\sigma_{v o l}^{0}(z, \theta)$.

Eq. 3 is an approximation neglecting the along track variation of the backscatter coefficient within the synthetic aperture.

Figure 3 shows an example where the volume backscattering coefficient is depth independent and has a cosine dependency on the incidence angle. The nulls of the antenna pattern show up in blue. The contribution of the volume clutter to the return waveform is computed by integration over all look angles at each equivalent depth, i.e. by row-wise integration in Figure 3.

\subsection{Internal layer contribution}

The internal ice layers are considered specular reflectors. The specular version of the radar equation is

$$
P_{L} \approx \frac{\lambda^{2} G_{g} G(0)^{2} \Gamma(z) E(z, 0) P_{t}}{(4 \pi)^{2}(2 R)^{2} L_{t x}}
$$

Here $\Gamma(z)$ is the subsurface Fresnel reflectivity at depth $z$, i.e. the reflection coefficient of the interface between two internal layers with refractive indices $n_{1}$ and $n_{2}$

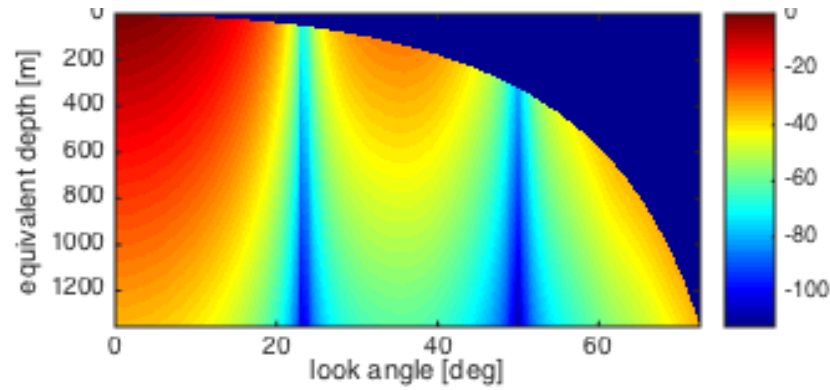

Figure 3 Volume clutter example (color scale in $\mathrm{dB}$ ). The blue area in the upper right corner represents the air, and the remainder of the plot represents the ice (the equivalent depth of the surface increases with increasing look angle).

$$
\Gamma(z)=R_{12}^{2}=\left|\frac{n_{1}-n_{2}}{n_{1}+n_{2}}\right|^{2}
$$

Mirroring the radar in the reflecting surface, Eq. 4 can be interpreted as the result of a one-way propagation geometry with twice the range and a transmission coefficient given by the Fresnel reflection coefficient of the internal ice layer. The specular version of the radar equation does not involve any integration, as the reflection is effectively confined to the first Fresnel zone, which is so small that the antenna gain can be considered constant.

The estimation of $\Gamma(z)$ and $E(z, 0)$ from the return waveforms of an airborne ice sounder is ambiguous, as only the product of the two parameters is observed. The same applies to the product of the basal backscatter coefficient and the two-way attenuation. The ambiguity is not a problem when assessing the performance of another (spacebased) radar at the location, where the ice sheet parameters were estimated, as the ambiguous parameters also appear as a product in the radar equation for that radar. The ambiguity is more problematic when assessing the performance at another location, and consequently various observational studies are used for regularization [2] by providing estimates of dielectric absorption [xx], firn depth [yy] etc.

\section{RESULTS}

The model has been implemented in Matlab. The runtime depends on the ice thickness and the number of range cells, but it is typically a few seconds, and it is dominated by the volume clutter computation, due to the integration over the extent of each range cell.

Figure 4 shows an example where a measured and a modeled return waveform are compared. The peak at $1130 \mathrm{~m}$ is the basal return. The peak at $600 \mathrm{~m}$ is irrelevant, as it is an artifact caused by double bounce reflection (ice aircraft - ice). The "shoulder" next to the surface peak is due to the firn, which typically has a high intensity. In this 


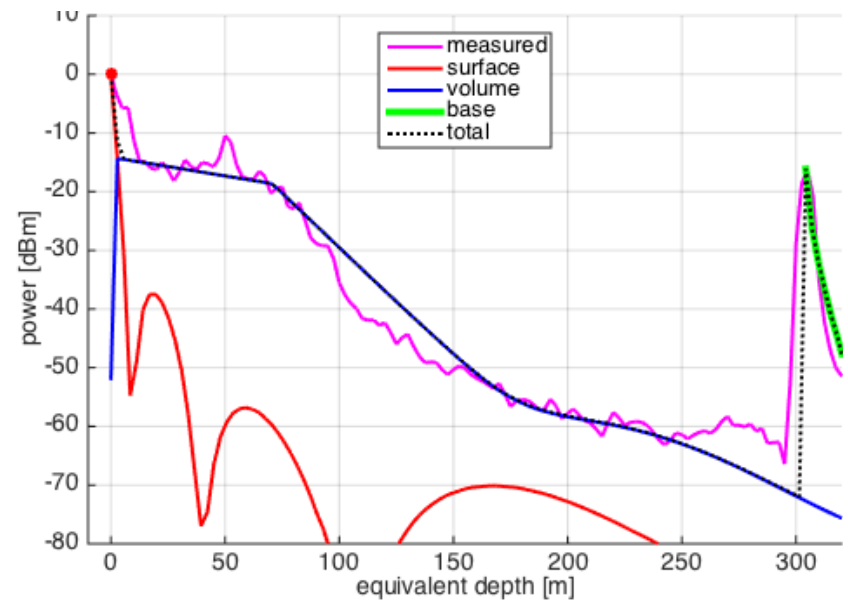

Figure 4 Return waveform measured with POLARIS over the ice shelf, Queen Maud Land, Antarctica. The modeled return waveform (black dotted) is the sum of the contributions from the surface, the volume clutter, and the bed. The measured and the modeled waveforms are both normalized to a maximum of $0 \mathrm{~dB}$.

case the firn contribution is modeled as specular reflection from internal layers, because such layers are visible in the radargramme, and the scattering pattern of the firn is narrow. This is seen when comparing Figure 1 and Figure 5.

\section{ACKNOWLEDGEMENT}

The backscattering and propagation model was developed as part of ESA-funded studies. The acquisition of POLARIS data in Antarctica was also funded by ESA as an addition to the IceGrav campaign - an airborne geophysics project lead by DTU in cooperation with the University of Texas, the Norwegian Polar Institute, the University of Bergen, Instituto Antarctico (Argentina), and the British Antarctic Survey.

\section{REFERENCES}

[1] J. Dall, S.S. Kristensen, V. Krozer, C.C. Hernández, J. Vidkjær, A. Kusk, J. Balling, N. Skou, S.S. Søbjærg, E.L. Christensen, "ESA's polarimetric airborne radar ice sounder (POLARIS): Design and first results", IET Radar, Sonar \& Navigation, Vol. 4, No. 3, pp. 488-496, June 2010.

[2] J. Dall, A. Kusk, H. Corr, N. Walker, A. Ginestet, B. Rommen, C-C. Lin, "On the feasibility of space-based radar ice sounding of the Antarctic ice sheet at P-band", ESA Living Planet Symposium, Prague, May, 2016.

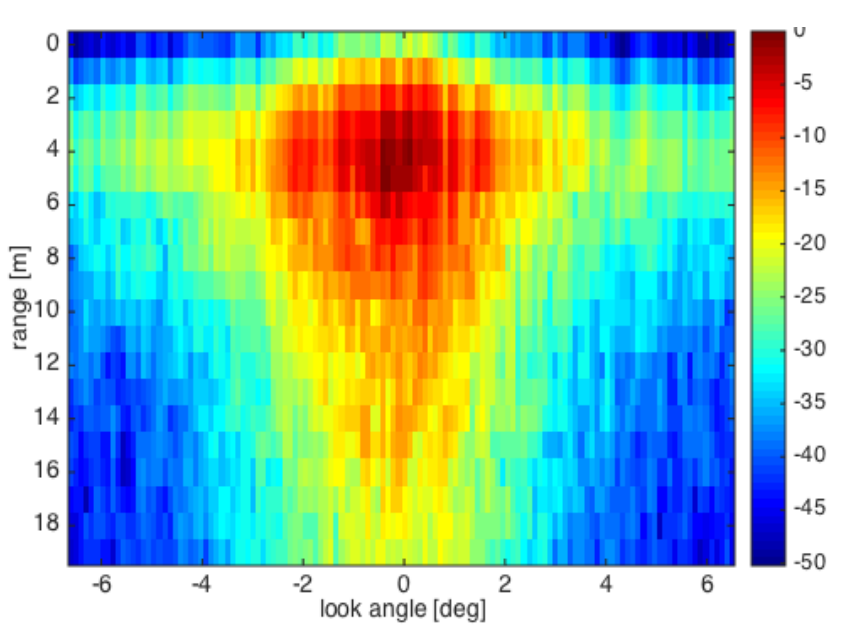

Figure 5 Scattering pattern of the surface and the firn layer in the interior of Queen Maud Land, Antarctica. The surface is at a range of $4 \mathrm{~m}$.

[3] J. Dall, A. Kusk, S.S. Kristensen, U. Nielsen, R. Forsberg, C-C. Lin, N. Gebert, T. Casal, M. Davidson, D. Bekaert, C. Buck, "Pband radar ice sounding in Antarctica", Proceedings of the IEEE 2012 International Geoscience and Remote Sensing Symposium, pp. 1561-1564, Munich, July 2012.

[4] F.T. Ulaby, R.K. Moore, A.K. Fung, Microwave Remote Sensing: Active and Passive, Vol. II, Addison-Wesley, London, 1982.

[5] G. Picardi, D. Biccari, R. Seu, L. Marinangeli, W.T.K. Johnson, R.L. Jordan, J. Plaut, A. Safaenili, D.A. Gurnett, G.G. Ori, R. Orosei, D. Calabrese, E. Zampolini, "Performance and surface scattering models for the Mars Advanced Radar for Subsurface and Ionosphere Sounding (MARSIS)", Planetary and Space Science, Elsevier, No. 52, 2004.

[6] Gudmandsen, P., Electromagnetic probing of ice. In: Electomagnetic Probing in Geophysics, p 321-348, Edt: James R. Wait, The Golem Press, Box 1432, Bolder, Colorado 80302.

[7] K. Matsuoka, J.A. MacGregor, F. Pattyn, "Predicting radar attenuation within the Antarctic ice sheet", Earth and Planetary Science Letters, Vol. 359-360, 15 pp. 173-183, ISSN 0012-821X, http://dx.doi.org/10.1016/j.epsl.2012.10.018, December 2012.

[8] S.R.M. Ligtenberg, M.M. Heilsen, M.R. van de Broeke, "An improved semi-empirical model for the densification of Antarctic firn”, The Cryosphere 5, pp. 809-819, 2011. 